\title{
Descubrimiento y rescate del Cementerio General de Santiago. Sus animitas, tumbas y santuarios en la Ruta Milagrosa de la Ciudad de los Muertos
}

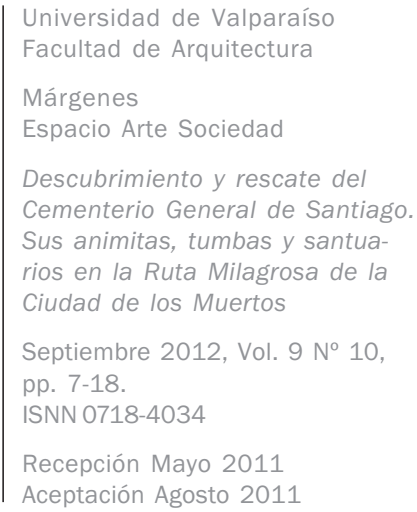

\section{Resumen}

Describiremos las herramientas y metodologías diseñadas y aplicadas para el descubrimiento y el rescate de los valores culturales del Cementerio General de Santiago. La realización de un Plano, de un Catastro Patrimonial, de las Evaluaciones Cuantitativas y Cualitativas y la investigación bibliográfica, son las herramientas para un trabajo que ha demostrado muy variadas utilidades como la creación de un decreto de monumento nacional, el control de una emergencia sísmica o la creación de rutas de turismo cultural. De este último punto nace una línea temática denominada la Ruta Milagrosa que está compuesta por dos santuarios populares como el Cristo Rico y el Cristo Pobre, y por afamadas tumbas o animitas milagrosas, como los mausoleos de Abelardo Núñez y de José Manuel Balmaceda y las sepulturas de la Carmencita, Romualdito y de la Novia.

Palabras claves

Cementerio General, patrimonio, tumbas, animitas.

(Cementerios patrimoniales, animitas, ruta patrimonial, ruta milagrosa, Cristo Rico, Cristo Pobre, José Manuel Balmaceda, Abelardo Núñez, La Carmencita, La Novia, Romualdito, religiosidad popular, la Ciudad de los Muertos, Arqueología Histórica de Cementerios, Catastro Patrimonial cementerio, Plano cementerio).

Discovery and recovery of Santiago's Central Cemetery. Animitas, graves and sanctuaries in the Miraculous Route of the City of the Dead

\section{Abstract}

The tools and methodologies designed and applied to discover and recover the cultural values of Santiago's Central Cemetery are described in this work. A plan, a heritage land registry, quantitative a qualitative assessments and bibliographic research were the tools created for this project. The project has been the base for different initiatives such as a national monument decree, a seismic emergency control plan and a cultural tourism route. As a part of the latter, there is a route called The Miraculous Route, which includes the visit to two popular sanctuaries: Cristo Rico and Cristo Pobre (Rich Christ and Poor Christ), and some other well-known miraculous graves or animitas, such as Abelardo Núñez and Jose Manuel Balmaceda mausoleums, and the graves of Carmencita, Romualdito and The bride.

\section{Key-words}

General Cemetery, heritage, graves, animitas 


\section{Découverte et sauvetage du Cimetière Général de Santiago. Ses animitas, les tombes et les sanctuaires dans la Route Miraculeuse de la Ville des Morts.}

\section{Résumé}

Ce travail décrit les caractéristiques des tombes miraculeuses et des sanctuaires d'une plus grande dévotion du Cimetière Général Santiago et du point de vue des sciences sociales - et non théologique révise le culte aux Cristes miraculeux et de plusieurs de ses tombes miraculeuses et vénérées par la religiosité populaire, comme les mausolées d'Abelardo Núñez et de Jose Manuel Balmaceda et les sépultures de la Carmencita, Romualdito et de la Fiancée. Le rejet aux injustices qui ont causé ces décès, la promotion des légendes jusqu'à être transformée en saints populaires, l'incarnation de leurs personnalités dans leurs tombes, la constatation d'un contact bénéfique avec le monde des morts et la célébration de la présence d'une âme miraculeuse, à travers des offrandes, des impôts, sacrifices et cadeaux.

\section{Mots clef}

tombes, miraculeuses, Cimetière Général, Balmaceda

\section{LA NECRÓPOLIS DE SANTIAGO}

Estamos orgullosos del legado que tenemos en el Cementerio General y nos sentimos honrados de pertenecer a esta cultura y de nacer en este lugar del mundo. Este patrimonio cultural es único, irreemplazable y grandioso, concentra lo mejor de muchas épocas y señala la patria de origen. Creemos que es importante respetar y conservar este yacimiento cultural y para lograrlo es necesario el compromiso de la ciudadanía beneficiada por este legado y también de sus dos herederos directos; los descendientes de los Fundadores y el Estado Chileno.

El Cementerio General posee una superficie estimada entre $\mathbf{8 0 , 5}$ y 86 hás., tamaño comparable a las macromanzanas del Parque O'Higgins o el Estadio Nacional. Creado en 1821, es la última morada de más de 2.500 .000 personas, la mayoría de la población de Santiago que murió entre 1821 y 1980 y que lo convierten en un registro y una fuente fundamental sobre los orígenes de buena parte de la sociedad santiaguina y chilena.

El Casco Antiguo protegido como Monumento Histórico, tiene una superficie de 28,5 hás., quizás hoy el más grande del país y en 70 manzanas se contabilizan 14.000 tumbas protegidas. De este total hemos identificado las $\mathbf{2 . 4 3 4}$ obras de alto valor patrimonial y sobre este universo hemos realizado nuestro análisis.

Sus principales colecciones patrimoniales son: el Relicario Nacional con 289 personajes históricos, la Colección de Arquitectura con 2.390 obras y la Colección de obras de Arte con 514 piezas. La institución tiene una edad de 190 años y la mayoría de las obras del Casco Antiguo fueron fundadas durante el auge salitrero época comprendida entre la Guerra del Pacífico y la Gran Depresión del 30.

El descubrimiento del valor patrimonial del Cementerio, permitió por primera vez encontrar e identificar la totalidad de sus monumentos relevantes y realizar una Evaluación Cuantitativa que permitiera dimensionar el conjunto. El posterior rescate fue posible gracias a la Evaluación Cualitativa de los valores culturales distinguidos como herencia y capital patrimonial. El estatus obtenido después de la Declaratoria de Monumento Histórico (Domínguez Balmaceda, 2009), permitió hacer tangibles las cantidades y hacer reales las cualidades culturales, renacimiento que incrementó meteóricamente el régimen de plusvalías ${ }^{1}$.

Esta protección legal reconoce la antigüedad como un factor positivo en la valoración y que hasta entonces era un factor negativo de obsolescencia, deterioro y vejez. Medimos el Plus Patrimonial de los valores culturales evaluados y la ponderación fue de 3,79 veces el valor material del conjunto identificado ${ }^{2}$.

\section{EL PLANO, EL CATASTRO PATRIMONIAL Y LA EVALUACIÓN CUANTITATIVA DEL CEMENTERIO GENERAL DE SANTIAGO}

Durante el trabajo investigativo sobre el valor histórico, urbano, arquitectónico y cultural del Cementerio, se realizó el catastro patrimonial de toda su superficie, haciendo énfasis en las 30 hectáreas de su casco antiguo ${ }^{3}$.

Tras varios años de estudio en torno al Cementerio, hubo muchas interrogantes que fueron imposibles de conocer. ¿Cuántas esculturas, cuántas obras de valor arquitectónico y cuántos personajes ilustres existen?; ¿Dónde están todos y cuáles son los más relevantes?; ¿Qué arquitectos han participado en su construcción y cuantas obras realizó cada uno?; ¿Cuántos monumentos, memoriales, santuarios y animitas existen y dónde están?; ¿Cómo ha sido la forma del Cementerio a través de su historia, en qué período histórico se desarrolló cada barrio y cómo ha sido el crecimiento y la expansión del Cementerio? y por último, ¿Cómo se han transformado las formas de entierro desde 1821 hasta hoy en día?

Ante la abismante escasez de conocimiento que envolvía el pasado del Cementerio General y frente a la fragmentaria información existente, surgió la idea de llevar adelante un catastro detallado que recolectara toda la información de interés patrimonial disponible. El principal obstáculo: la inexistencia de un plano detallado de la planta del Cementerio.

Se comenzó midiendo los anchos de las calles y las dimensiones de los patios, para luego superponer esta información con la fotografía aerofotogramétrica, armando así la estructura general de la planimetría. Luego, se elaboraron planchetas 
individuales para cada patio levantando en terreno cada una de las construcciones.

Sobre este croquis se prosiguió seleccionando las obras de interés patrimonial que sumaron un total de 2.728 fichas fotográficas (2.434 dentro del Casco Antiguo), registradas en alrededor de 23.000 fotos digitales. La información recolectada precisa:

- La ubicación exacta de cada obra y su contexto próximo.

- El nombre de su fundador, de la familia propietaria, de la colectividad o institución.

- Personas de relevancia histórica como próceres de la patria, intelectuales, presidentes, políticos, ministros de Estado, escritores, poetas, músicos, artistas, empresarios, benefactores públicos, etc.

- La arquitectura de la tipología de entierro (bóveda, mausoleo, hipogeo, etc.).

- El autor (arquitecto o escultor).

- El año de construcción (o del primer entierro o el año de la venta del título).

- Los detalles constructivos y ornamentales.

- Las inscripciones, epitafios, placas recordatorias, etc.

- Las esculturas (obras originales de autor, estatuas, bajorrelieves, etc.).

- Las artes y oficios aplicados (vitrales, cerrajerías, jarrones, etc.).

- Distintos aspectos inusuales, curiosidades, etc.

Adicionalmente se ficharon las piezas arquitectónicas de mayor relevancia como la iglesia, la puerta La Paz, el acceso Recoleta; la Plaza La Paz y sus portales; el muro perimetral, etc.

Terminada la recolección de información, se contó con una inmensa base de datos real y objetiva, sobre la que se pudo comenzar la clasificación, el refinamiento y la selección de los casos más significativos.

Más allá de los datos duros del catastro y del plano, la información recogida permitió crear dos importantes fuentes de referencia para continuar con la investigación patrimonial del Cementerio.

En primer lugar se ordenaron cronológicamente las 910 obras de mayor interés arquitectónico y a partir de este registro se pudo observar detalladamente los procesos de cambios de la arquitectura de las tipologías y de las formas de entierro a través de su historia, detectando las transformaciones de las tradiciones culturales y de las mentalidades ligadas a la idea de la muerte, desde $1821^{4}$.

La segunda fuente referencial desarrollada para la investigación consistió en relacionar la planta del Cementerio con las fechas de las obras, lo que permitió conocer las trasformaciones de la forma urbana del Cementerio y sus procesos de crecimiento, la constitución de sus barrios, la distribución socio-espacial en el tiempo, la densificación y el reciclaje, y otros fenómenos urbanos que arrojaron interesantes similitudes con Santiago a través de su historia y que entregan reveladores datos de una ciudad que ya ha desaparecido.

Además, la existencia de un plano y el georeferenciamiento de los puntos de interés, posibilitan el nacimiento de la actividad cultural y el cuidado y monitoreo de las colecciones. Ahora resulta posible planificar rutas de turismo cultural, seleccionan- do los contenidos según intereses como la Ruta Milagrosa (de las Animitas), la ruta del Panteón de los Presidentes, de los próceres de la Independencia, de escritores y artistas, de esculturas, de arquitectura destacada y las posibles combinaciones.

Asumiendo como propias del proyecto, algunas responsabilidades que fueron demandando las circunstancias, usamos el Plano para la elaboración del Catastro de Daños del Terremoto del 2010 (Domínguez Balmaceda, 2008), para facilitar la detección de los robos de obras de arte y para realizar un monitoreo permanente de la evolución de la emergencia en las 28 hectáreas del Casco Antiguo.

\section{EVALUACIÓN CUALITATIVA DEL CATASTRO PATRIMONIAL}

Para desenterrar los secretos del pasado de la necrópolis, hubo que inventar una disciplina especializada en cementerios históricos, inexistente hasta entonces entre las ramas de las ciencias sociales y sin referentes conocidos en Latinoamérica o Europa. El lente de observación fue la mirada patrimonial que engloba saberes como historiografía tradicional, historia de la arquitectura, historia del arte, arqueología histórica, urbanismo, paisajismo, geografía, arquitectura, restauración, sociología, genealogía, antropología, derecho, teología, filosofía, fotografía y museología. Con estas herramientas intelectuales evaluamos cualitativamente los valores patrimoniales del Cementerio y desempolvamos parte de las raíces de la sociedad santiaguina. Estos instrumentos de excavación y medición sirvieron para determinar la envergadura de los hallazgos con métodos científicos, todos reproducibles y objetivos.

Los valores culturales identificados en cada obra se definieron como los componentes irreemplazables e irrepetibles de originalidad de cada monumento, que representan creencias culturales y religiosas representativas de una civilización particular, que son capaces de hacer presente otro tiempo y personas del pasado, que encarnan una identidad común y poseen valores estéticos, urbanísticos y paisajísticos notables y singulares que evidencian procesos de evolución cultural, urbano, arquitectónico, artístico y social, y también hechos significativos que cambiaron la historia.

Identificamos 7 dimensiones patrimoniales para cada sepultura:

1. Antigüedad

2. Celebridad

3. Valor Arquitectónico

4. Valor Artístico

5. Aporte Urbano

6. Significado Cultural

7. Posesión de reliquias

Para nuestra evaluación, excluimos la última de las categorías ya que asignar un rango objetivo resulta impracticable porque a las cenizas y a los restos óseos se les atribuyen condiciones sobrenaturales, sacras y rituales. Sin embargo para identificar la importancia de estas sustancias las imaginamos como el polvo de oro que anima a las tumbas. Esta encarnación de los muertos en sus tumbas es descrito por la religiosidad popular como presencia de ánima, alma o espíritu. Desde el punto de vista de las ciencias sociales describimos este fenómeno como memoria histórica, cápsula de tiempo, voces del pasado, re- 
gistro arqueológico, etc. y en definitiva es un patrimonio inmaterial originario, único e irremplazable.

\section{ÁNIMAS, ANIMITAS Y TUMBAS MILAGROSAS}

Las animitas son moradas para las ánimas. Las tumbas son animitas con restos humanos. Las animitas que están fuera de los cementerios son monumentos funerarios sin restos (cenotafios).

Una ánima es la presencia de una persona muerta. Su presencia está asociada a un lugar específico y depende de la existencia de una sepultación (cuerpo o cenizas) o de un suceso trágico. Este lugar, sirve de espacio de comunicación entre los vivos y los muertos. Este tipo de comunicación se realiza en animitas, cementerios, monumentos o iglesias.

Las animitas fuera de los cementerios generalmente son construidas a consecuencia de un suceso trágico que terminó con la vida de una persona por accidente, homicidio, fusilamiento, etc. ...lo que la religión popular señala es que el alma es lo que queda perdido y errante en búsqueda de su cuerpo faltante (Ojeda \& Torres, 2011, p. 6). Según la religiosidad popular, lo arbitrario y súbito de la muerte, impidió a la persona hacerse conciente de su destino fatal, quedando el ánima en pena según la idea cultural del purgatorio, en un umbral, a medio camino entre el mundo de los vivos y el de los muertos, lo que le otorga la capacidad de interceder entre lo humano y lo divino. En la iconografía latina-judeo-cristiana las ánimas son representadas como mensajeros, intermediarios, ángeles o querubines. Las prácticas rituales indican que las ánimas se presentan cuando los muertos son recordados en el lugar, son invocados, tributados y cuando se les reza en voz alta o baja.

Todas las tumbas, monumentos funerarios, cenotafios o columbarios de los cementerios, poseen el potencial de encarnar sus ánimas y de ser lugares para la práctica del culto a Ios muertos. El Cementerio General en sus 80 hás., posee más de 40.000 construcciones y 2.500 .000 personas enterradas. El Casco Antiguo (1821-1930) posee 14.400 tumbas en 28,5 hás. Estudiamos 2.700 puntos valor patrimonial y distinguimos 910 obras de valor arquitectónico, 514 obras de arte, al menos 289 personajes célebres, todo en un parque de 180 años. En este perímetro y dentro de nuestra clasificación de patrimonio inmaterial destacan 2 santuarios y 5 santos populares que presentan rasgos pronunciados de culto y que revisaremos más adelante ${ }^{5}$.

\section{SANTUARIOS POPULARES EN EL CEMENTERIO GENERAL: EL CRISTO RICO Y EL CRISTO POBRE}

Son imágenes religiosas de fierro fundido (o de bronce) que representan cristos crucificados y sus singulares nombres provienen del S.XIX. La presencia de las imágenes revela la vocación plural e igualitaria de un cementerio general, donde se reúne a ricos y pobres en un mismo recinto, y al mismo tiempo, delata dos rasgos profundos de la sociedad chilena: su estratificación polarizada y la fuerte segregación espacial entre ricos y pobres, tanto en la ciudad de los vivos como en la de los muertos, durante todo el período republicano.
Estos cristos no son animitas, sino que santuarios que la religiosidad popular les asigna la condición de milagrosos y cuyas prácticas devocionales semejan las de las animitas y de las tumbas milagrosas.

\section{CRISTO RICO}

Ubicación: Intersección de avenidas O`Higgins y Arriarán

Tipología: Hito urbano ubicado al centro de una plazoleta de intersección de antiguas avenidas estructurales. Está formado por una imagen de Cristo crucificado en cruz de madera puesta sobre una pira funeraria o túmulo de mampostería de piedra.

Descripción: Morfología propia de los atrios o patrios de sepultación de los pobres durante la colonia, en donde se erigía al centro una pira de piedras provenientes de las excavaciones y que sostenían la cruz central que indicaba la sacralidad del recinto y el sepulcro colectivo de los pobres. Esta tradición iconográfica se heredó en el Cementerio General después de prohibidos los entierros al interior de las iglesias coloniales, realizada por 0`Higgins en 1821. El Cristo Rico es testimonio de ello, ya que se ubica en la intersección

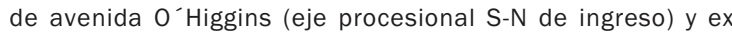
avenida Central, hoy avenida Arriarán (eje P-O perpendicular que remata al oriente), siendo una imagen cultural que identifica una inmensa tumba anónima y común. En este centro del diseño urbano del reciento aparece el Cristo Rico como figura clave en el cruce y la intersección de dos realidades opuestas, dándole al camposanto un hito urbano cuyo significado es la esperanza en la resurrección y la vida eterna, encarnando el espíritu cristiano de la época, en un elemento urbano concreto que aún continúa intacto.

Devociones: Culto popular que busca el contacto directo con Dios y los tributos característicos son la quema de velas, ofrendas florales, regalos, plaquitas de agradecimiento por favores concedidos a cambio de mandas y juramentos. Es un punto de detención dentro del recorrido de muchos deudos por el Cementerio.

\section{CRISTO POBRE}

Ubicación: Intersección de calles Calvario y Primera de Tilo

Tipología: Pira funeraria con crucifixión en intersección de calles.

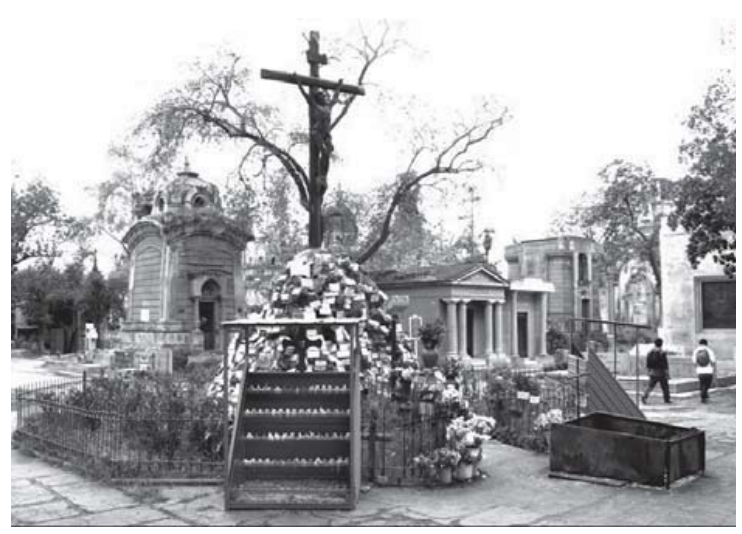




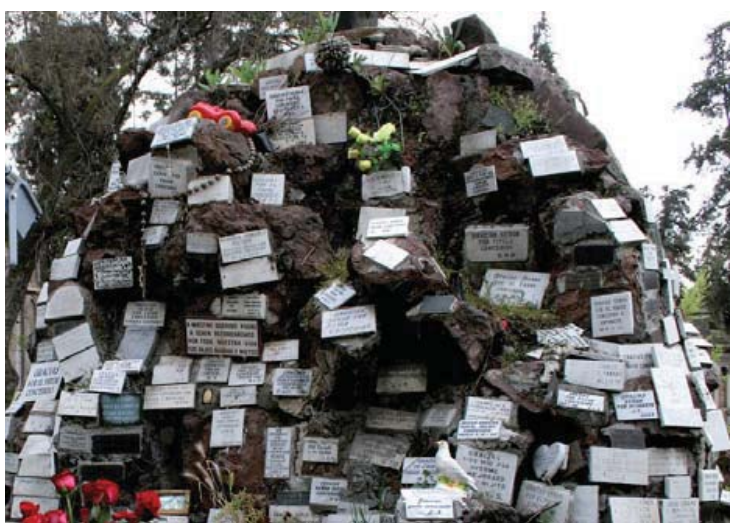

Figura 2 Cristo Rico, Patio 50, detalle.

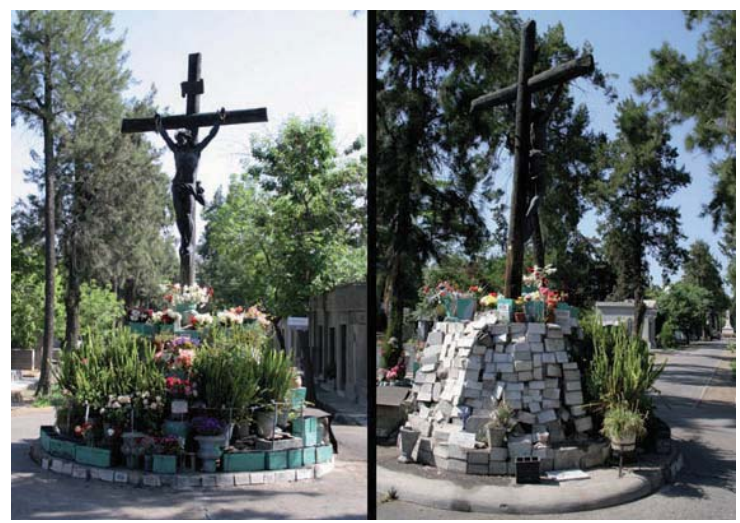

Figura 3 Cristo Pobre, Patio 64

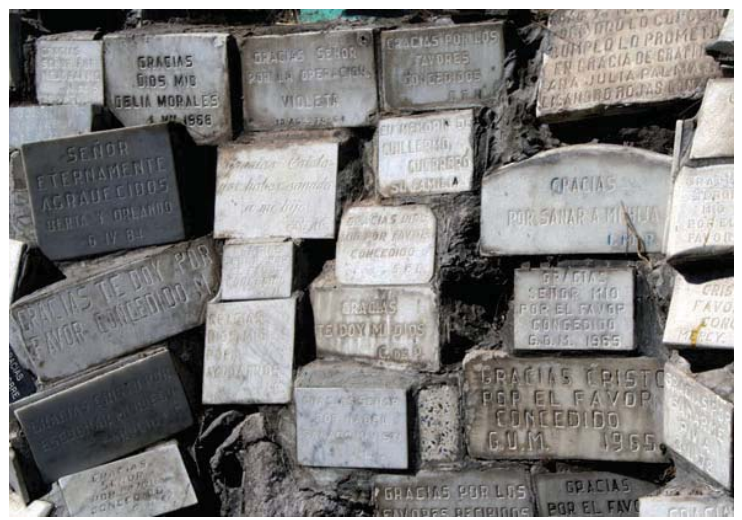

Figura 4 Cristo Pobre, Patio 64, detalle
Descripción: La fisonomía es casi idéntica a la del Cristo Rico. Sin embargo no está ubicada en un punto tan neurálgico ni en una plazoleta y aunque no es tan concurrida, tiene marcas potentes de devociones populares.

El apellido de pobre, se originó porque cuando ambos cristos fueron erigidos alrededor de 1890, esa zona era de patios de tierra para los pobres y el Cristo Rico estaba en la zona de los mausoleos más opulentos de la época. Se presume que los Cristos datan de la década de 1830 y que originalmente estaban en las intersecciones de la calles Infante con Bello e Infante con Sacié, siendo reemplazados por fuentes de agua a fines del S.XIX.

\section{ANIMITAS O TUMBAS MILAGROSAS DEL CEMENTERIO GENERAL. 5 CASOS}

\section{PRESIDENTE JOSÉ MANUEL BALMACEDA}

Ubicación: Intersección de las avenidas O`Higgins y Primera de Tilo.

Tipología: Mausoleo monumental, construido en 1915 por el arquitecto Tebaldo Brugnoli, después de un tiempo en que el cuerpo del ex presidente estuvo escondido en distintas tumbas (según la tradición mientras era perseguido, estuvo por cinco años en el mausoleo personal de Manuel Arriarán el entonces director del Cementerio General, monumento que colapsó durante el terremoto del 2010).

Descripción y devoción: Escondido en la legación argentina de los revolucionarios victoriosos que lo buscaban para lincharlo, Balmaceda se suicidará el 19 de septiembre de 1891, al día siguiente de haber terminado su período presidencial y tras haber perdido la guerra contra el Congreso, la oligarquía y la Armada. Fue odiado ardientemente por sus enemigos y buscó inmolarse para evitar el revanchismo con sus colaboradores caídos junto a él. Su sacrificio lo convirtió en una figura histórica de gran brillo y en el Cementerio General es uno de los muertos de mayor celebridad. Fue enaltecido por el pueblo como un santo popular y la historia le otorgó a Balmaceda la condición de mártir de la república y la tradición lo canonizó venerándolo y recurriendo a sus atributos milagrosos.

Según la religiosidad popular, el suicidio no conlleva ánimas en pena, porque el suicida al ser conciente de su destino muere prevenido. Sin embargo la opinión pública ve en Balmaceda a una persona que desea vivir y cuyo sacrificio fue una opción en defensa de la paz interna del país, de la Constitución y de la Presidencia de la República y también para aliviar el sufrimiento de sus familiares y colaboradores.

En consecuencia, en su mausoleo su ánima es invocada con frecuencia, producto de su fama de cumplidor de favores y mandas. ¿Santo popular? ¿Ánima milagrosa? ¿Muerto célebre?

Sus fieles recurren a él con peticiones por escrito y el mármol de la fachada es persistentemente llenado de graffiti y en el interior son arrojados papeles y cartas con peticiones. Balmaceda, ayúdame a tomar buenas decisiones; Cuida a mi familia; Ayúdame a pasar de curso y cuida a mi familia; Te pido por todas las familias y la gente muertas; Te pido para que siga la lucha intensa de los estudiantes; Te pido por mis hermanos y que ya no los tengo conmigo y que pase de curso; Te 


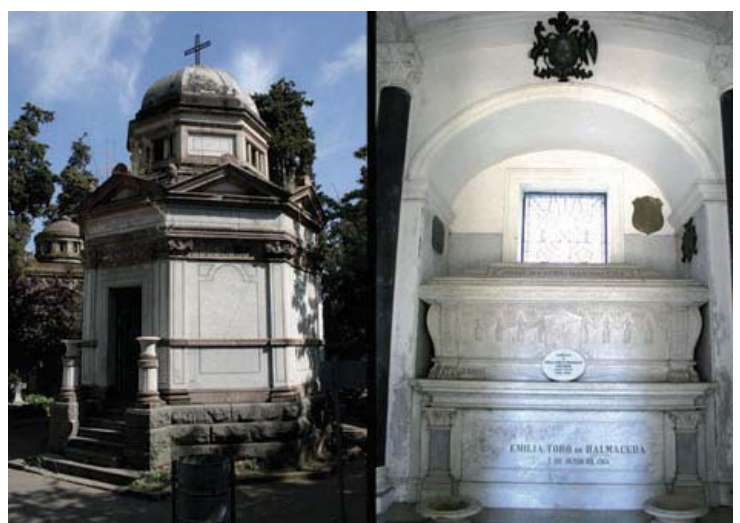

Figura 5 José Manuel Balmaceda, Patio 68

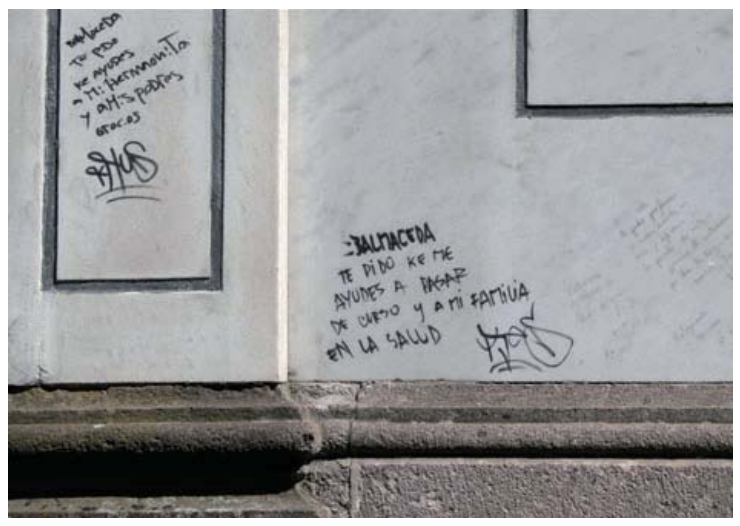

Figura 6 José Manuel Balmaceda, detalle

pido por favor que me cuides durante mi vida y ayúdame en la prueba de historia. Gracias de antemano. Que dios te tenga en sus brazos; Pedimos para que nos vaya bien en estos años de carrera, Bendiciones; Balmaceda, ya estoy sano.

El blog Urbatorium ${ }^{6}$, en un artículo titulado Mausoleo de José Manuel Balmaceda: La canonización escolar de un infortunado ex presidente, describe aspectos sobre la escolaridad de sus devotos y también da testimonio de la existencia de este culto a treinta años del suicidio de Balmaceda y cita un testimonio de Joaquín Edwards Bello escrito en 1921 en Crónicas: Personas de diversas categorías, generalmente humildes, le piden favores. Siempre está cubierta de peticiones o mandas. Un estudiante le suplica que le ayude a salir bien en los exámenes. Otro le solicita ayuda para que lo quiera una chiquilla Ilamada Estela. La obrera María S. le pide que libre a su marido del alcoholismo. La tumba de Balmaceda se parece a las "animitas" de extramuros.

Desde el 2009 hay un cartel que prohíbe hacer rallados, pero no se abrió un canal alternativo para que los fieles puedan encausar su fervor.

\section{ABELARDO NÚÑEZ (EL PROFESOR)}

Ubicación: Esquina sur poniente de la intersección de calles Sazié y Dávila.

Tipología: Mausoleo de sillería de piedra caliza y albañilería de cal y canto, de la década de 1890.
Descripción: Fue el fundador y prócer de las escuelas normalistas, autor de los libros Organización de las Escuelas Normales, Silabario y El lector Americano, fue un nombre conocido para generaciones de escolares que aprendieron a leer y a escribir de sus textos. Su fama se fomentó por rumores de que hubiera sido jefe del servicio de inteligencia chilena en Lima durante la Guerra del Pacífico y se asociada al personaje de la literatura apodado El Profesor en Adiós al séptimo de línea.

Las peticiones se asocian al éxito en el rendimiento escolar y se manifiestan a través de mensajes. Pese a ser una devoción antigua hace algunos años fueron borrados los rallados del mármol y fue pintada la piedra, no habiendo evidencias actuales del culto.

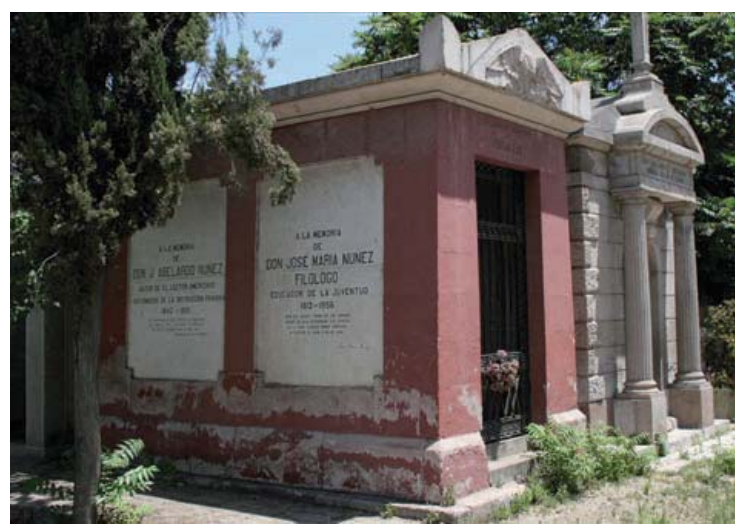

Figura 7 Abelardo Núñez, Patio 24

\section{LA NOVIA, NOVIECITA O LA NOVIA ORLITA}

Ubicación: Patio $\mathrm{N}^{\circ} 70$, en fachada norte de patio interior, que da la espalda a calle Limay y que se accede por calle Nicolás Vicuña.

Tipología: Mausoleo de Orlita Romero Gómez, tipo “capilla” de albañilería armada estucada y construido en la década de 1940.

Descripción: Una placa de mármol instalada por su madre en ocasión de los 20 años de su muerte sirve de introducción:

13 de abril de 1943

Hijita Orlita,

En tu breve existencia

distes luz a mi vida

con tu bendita presencia.

13 de abril de 1961

Los ángeles vuelven

a Dios.

Tu mamacita

La historia del culto a la Novia, nace de la llamativa reacción que tuvo la madre de Orlita tras la muerte de su hija y que según versiones confiables, la habría embalsamado para conservar su belleza y la habría vestido de blanco para sus funerales. Otra versión dice que la madre doliente, habría cumplido periódicamente con la costumbre cepillar el pelo y mantener inmaculado el cuerpo de la joven. 
La tradición oral da más versiones de la identidad de esta santa popular. Se dice que se trata de una novia que murió el día de su matrimonio al rodar por las escalinatas que la llevaban al altar, no pudiendo concretar su compromiso. También pudiera ser una mujer que murió de pena o de un infarto tras ser dejada plantada en su matrimonio.

Como contrapunto la historia forense habla de una joven de 17 años que muere en 1943 de peritonitis.

Lo cierto es que para los fieles se ha convertido en la santa de los enamorados que piden que el amor sea para siempre; de amantes desgraciados que buscan una nueva oportunidad; de novias para tener suerte en el matrimonio y que la unión dure para siempre; pololas que esperan impacientes ser pedidas en matrimonio; deseos de esperanza para amores imposibles; escolares para el éxito en sus estudios; salud; cuidados para la familia; etc.

Los rallados se disputan los espacios de los muros del mausoleo e invaden las tumbas vecinas. Abundan también los "tags" (firmas de grafiteros) que se sobreponen en una saturación total que impide dar lectura a muchos mensajes. También se introducen cartas con peticiones por la puerta (algunos con plata), se dedican corbatas escolares y ofrendas florales.

\section{LA CARMENCITA}

Ubicación: Patio $\mathrm{N}^{\circ} 82$, avenida Limay vereda norte, entre calles Nicolás Vicuña y Alejandro del Río.

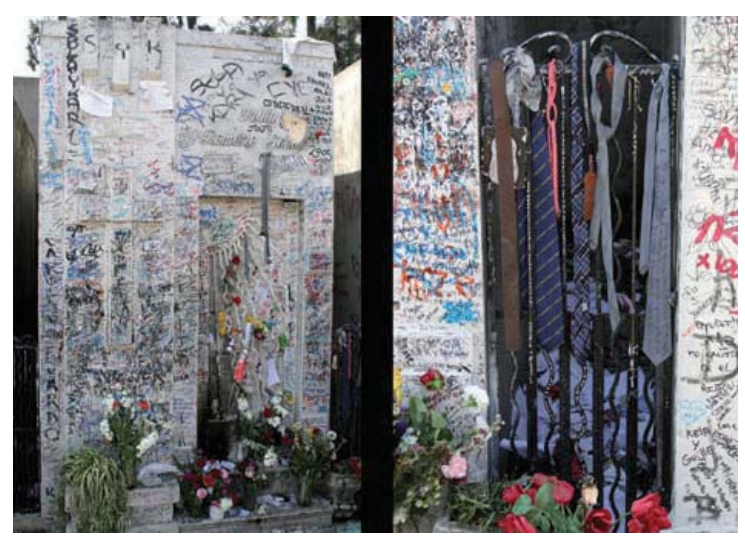

Figura 8 La Novia, Patio 70

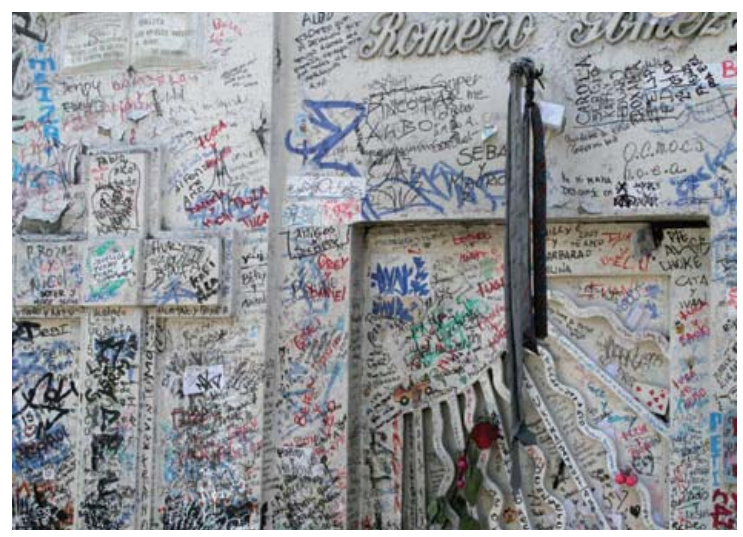

Figura 9 La Novia, detalle
Tipología: Sepultura de Margarita del Carmen Cañas Cañas. Bóveda subterránea de hormigón armado.

Descripción: La tradición narra que en esta sepultura descansa el alma de una niña de 9 años, violada y asesinada en 1949, por un criminal que no pudo ser capturado ni castigado.

La tumba atrae devociones que se manifiestan en quema de velas, placas de agradecimiento, tarjetas manuscritas, muñecas y juguetes infantiles y por sobre todo ofrendas florales.

Su localización en Limay, en una vía estructurante del camposanto desde la década de 1940, cuando se abriera al público la puerta sobre avenida Recoleta (y hoy con la estación Cementerios del Metro), posiciona a esta tumba en la ruta obligada de muchos fieles que visitan a sus familiares y hacen la detención o el desvío para ver a la Carmencita.

Es quizás la tumba milagrosa más conocida del Cementerio y como lugar de devoción se ha ganado el convencimiento y la fe de los fieles.

Queda además de manifiesto la existencia de dos realidades paralelas sobre la identidad de la Carmencita; la versión forense que habla de una mujer de 37 años que murió en la Posta Central por una reacción adversa a la anestesia y la versión que da la lectura de las evidencias del culto popular y que rodea al mito de la niña asesinada.

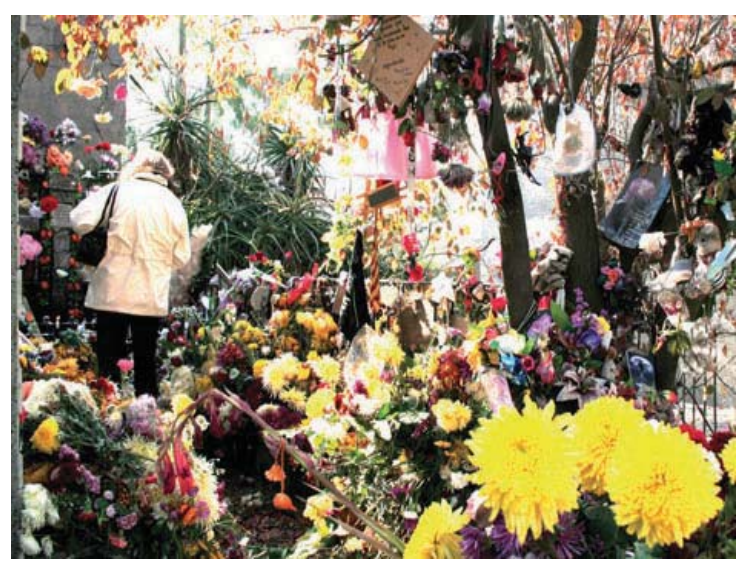

Figura 10 La Carmencita, Patio 82

\section{ROMUALDITO}

Ubicación: Patio $\mathrm{N}^{\circ} 34$, anexo del pabellón $\mathrm{N}^{\circ} 4$, tercera corrida, asequible por calle Dávila vereda sur, al oriente de calle Alejandro del Río

Tipología: Sepultura de Romualdo Ivani Zambelli, nicho de pabellón de la década de 1930.

Descripción: La animita de Romualdito de la esquina de la Alameda con San Borja es quizás la más famosa de Santiago. Su tumba es un tímido eco de la actividad que suscita su devoción, pero presenta signos persistentes de culto popular y fama de milagroso. 


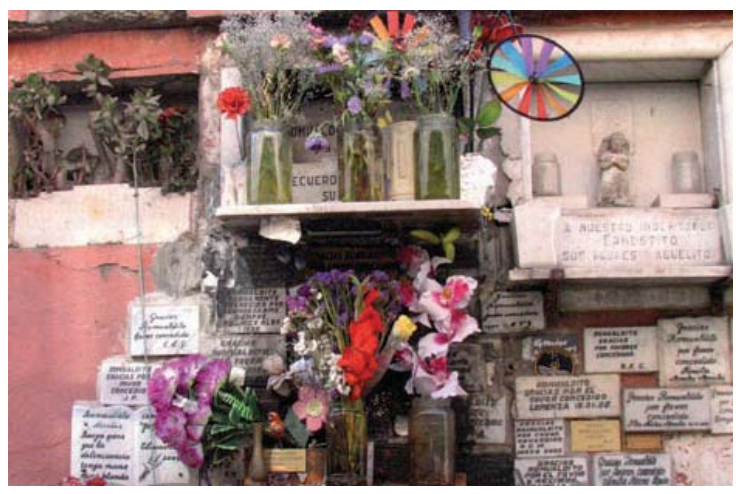

Figura 11 Romualdito, Patio 34

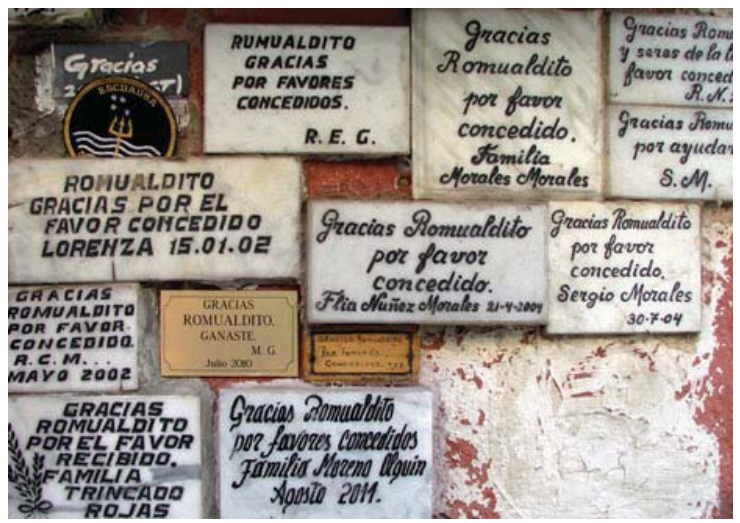

Figura 12 Romualdito, detalle

Sobre la identidad de este santo también existe controversia. La versión forense habla de un mecánico de 41 años acuchillado en el corazón por un asaltante, hecho ocurrido en 1933 en el lugar de su animita. Sin embargo la versión más aceptada cuenta de un hombre con deficiencia mental, lo que probablemente hizo que la gente lo viera como a un niño. Vivía en San Bernardo y en el trayecto que recorría para llevarle el almuerzo a su padre en un hospital, fue asesinado a sangre fría para robarle un manto de castilla (prenda apreciada en la época) y nunca se supo la identidad del homicida.

\section{DEVOCIONES POPULARES, EL CULTO A LOS MUERTOS Y REFLEXIONES SOBRE ANIMITAS DE CEMENTERIO}

Los cementerios son las ciudades de los muertos y representan simbólicamente el lugar intermedio entre la realidad natural y la sobrenatural; entre lo físico y lo metafísico; entre la vida y la muerte; entre el día y la noche; entre el pasado y el futuro; entre el principio y el final. El culto a los antepasados es una actividad espiritual que conecta ambos mundos y en donde los muertos sirven de intermediarios ante la divinidad, como análogamente se podría comparar con el papel de los santos y de los ángeles en la religión católica romana y el culto a los patronos al interior de las iglesias.

Al estudiar la evolución de las necrópolis desde la óptica de la Arqueología Histórica de Cementerios, una de las primeras observaciones que surgen es que las creencias en torno a la muerte y el culto a los muertos cambian permanentemente a lo largo del tiempo (Ariès, 1983). Las creencias sobre los mis- terios de la muerte son fundamentales para darle el sentido a la vida en toda cosmovisión, religión o tradición cultural. Las tumbas al ser construcciones esencialmente simbólicas, son la encarnación de una creencia y la existencia de rituales hace que la cosmovisión que originó esa obra sea una realidad presente, y que el mundo que representa sea verdadero y capaz de traer al presente creencias pasadas, fragmentos físicos y arqueológicos de mundos y nombres de hombres de otros tiempos. Esta compleja pieza de memoria urbana, es contenedora de tiempos pasados y su capacidad de ser espejo de una sociedad a través del tiempo, es uno de los hechos más valorables de la dimensión patrimonial de los cementerios históricos.

Esta visión metodológica descrita, será la herramienta de análisis e interpretación del Cementerio General y sus animitas, santuarios y tumbas milagrosas.

El culto popular en animitas, santuarios o tumbas milagrosas es una tradición de larga data en el Cementerio General y en otros cementerios del país. En sus santuarios la presencia de Dios y el contacto con lo sobrenatural se hace presente en el Cristo Rico y el Cristo Pobre. El nacimiento de estas prácticas en algunas sepulturas generalmente es consecuencia de muertes trágicas e injustas.

Al quedar impunes los responsables de una muerte criminal, queda insatisfecha la necesidad de desagravio de las víctimas, la que se traduce en la posterior ritualización del duelo colectivo con las prácticas de la religiosidad popular. La creencia de la existencia de un ánima milagrosa da como consecuencia que esta ánima sea querida y temida a la vez, ya que el sentido común y el miedo a lo desconocido, a los espíritus y apariciones, ordena al instinto natural, no perturbar a las ánimas y sus animitas, ni a los muertos y sus tumbas. Un ánima, anima la materia y las piedras de las tumbas o las latas y ladrillos de una animita, otorgándoseles la facultad de bendecir la suerte de sus devotos o la de maldecir la de sus profanadores.

La presencia del ánima de los muertos, también resulta muy ventajosa para los vivos de buenas intenciones, ya que según la tradición este tipo de ánimas poseen atribuciones similares a las de los ángeles y son buenos intermediarios y mensajeros entre los mortales y la divinidad eterna. El culto a los muertos es un ritual de apaciguamiento, petición y agradecimiento y las demandas tienen forma de ruegos, compromisos y contratos simbólicos. En los casos estudiados, la devoción popular se enciende de boca en boca incrementando la fama de la tumba milagrosa y cumplidora de favores y el consiguiente fervor, dando origen a santos populares. La "bendición" y la "virtud" de estas tumbas provienen de su potencial de ser buenos umbrales y canales de comunicación entre los vivos y los muertos y donde poder acudir pidiendo el socorro de poderes sobrenaturales milagrosos o simplemente de dádivas de la divinidad.

Los agradecimientos y las ofrendas son votivas y de naturaleza simbólica como la vela / luz / alma / fuego eterno; las flores / vida / fertilidad y la palabra / placa de agradecimiento y también bienes para las ánimas como juguetes, baberos $u$ objetos de valor personal de los devotos como prendas de vestir, etc. La luz atrae en la oscuridad e invoca al ánima. Las flores serán un cuerpo transitorio donde se anime la memoria 
del muerto, según Violeta Parra en el Rin del angelito: Cuando se muere la carne, el alma busca su sitio, adentro de una amapola o dentro de un pajarito.

Balmaceda es quizás el caso más evidente de la sed de justicia post mortem y de la restauración del nombre de la víctima de una muerte trágica. En otros paradigmas trágicos como un inocente víctima de la delincuencia, la novia frustrada o la niña abusada por un pederasta homicida, esta canonización popular va de la mano de la idealización de los rasgos de la historia que rodea a la presencia de las ánimas milagrosas y la tradición oral les adiciona rasgos de inocencia y pureza, lo que da necesariamente como resultado la creación del mito en torno a las tumbas y las contradicciones entre la versión forense y la versión popular.

\section{LA RUTA MILAGROSA}

El Cementerio General es un inmenso yacimiento cultural, rico en expresiones que buscan la trascendencia, denso en información y complejo en sus lenguajes de comunicación. Es el más importante museo de sitio de la historia de los personajes ilustres de la República, es una de las colecciones de arquitectura funeraria más grande de América y es quizás el más grande museo de esculturas del país.

En base al conocimiento recabado por el proyecto La Ciudad de los Muertos y del Catastro Patrimonial, hemos determinado con precisión cuales son los distintos valores patrimoniales que enriquecen al Cementerio General y este saber nos permite planificar el desarrollo de rutas patrimoniales. Así nacieron la Ruta Bicentenario por las tumbas de los miembros de la primera Junta de Gobierno, la Ruta del Panteón de los Presidentes de la República, etc.

En ocasión de este encuentro de estudiosos sobre la materia, hemos creado la Ruta Milagrosa por los $7(+1)$ puntos más importantes de fervor popular del Cementerio. El plano indica los puntos de interés y permite hacer una visita auto guiada que dé presencia y difusión a este culto y se espera que el nuevo recorrido sirva para valorización patrimonial, para la mayor apropiación popular, para la reafirmación de la identidad, además de aliviar angustias, dar esperanzas en casos desesperados, mitigar anhelos imposibles y sobrenaturales o simplemente milagros.

\section{¿PORQUÉ ESTUDIAR UN CEMENTERIO? UNA APRECIACIÓN} PERSONAL SOBRE EL DESCUBRIMIENTO DE UN TESORO

Me crié en un mundo moderno-científico donde la muerte era tabú, donde hablar de los muertos estaba prohibido y donde los cementerios eran los lugares de miedo, dolor y olvido. El cine y la televisión foránea me mostraron que se trataba de lugares de fenómenos poltergeist, con zombis estilo thriller y hogar de fantasmas, vampiros y hombres-lobo. Cuando conocí el Cementerio General se me produjo una contradicción que alimentó mi curiosidad por conocer sus secretos. Donde debía ver actividad paranormal, vi paz; donde debía ver el horror de halloween, vi la devoción del $1^{\circ}$ de noviembre; donde debía ver monstruos, vi personas caídas en desgracia y chilenos en la historia; donde debía ver demonios, vi ángeles y ánimas

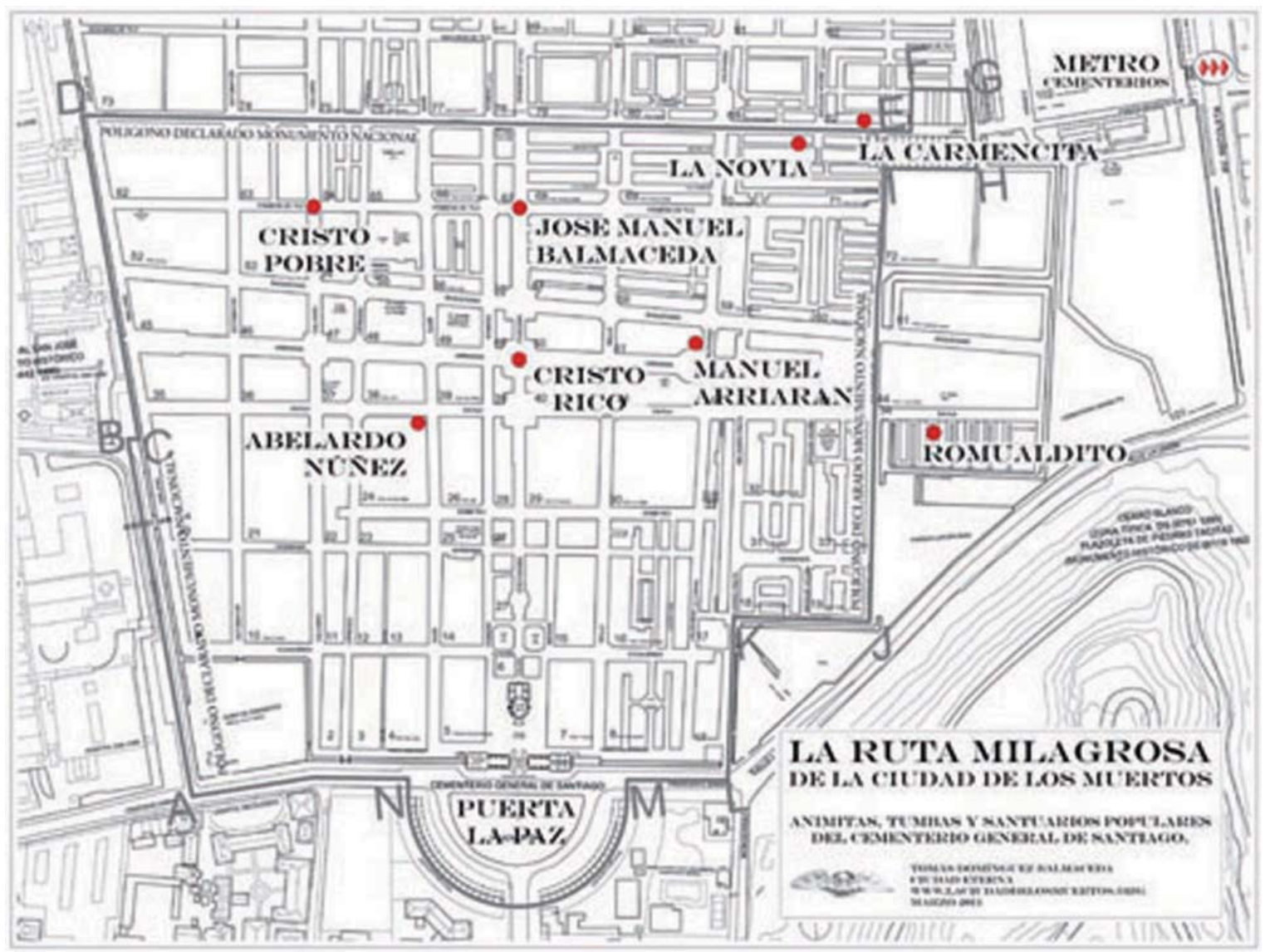




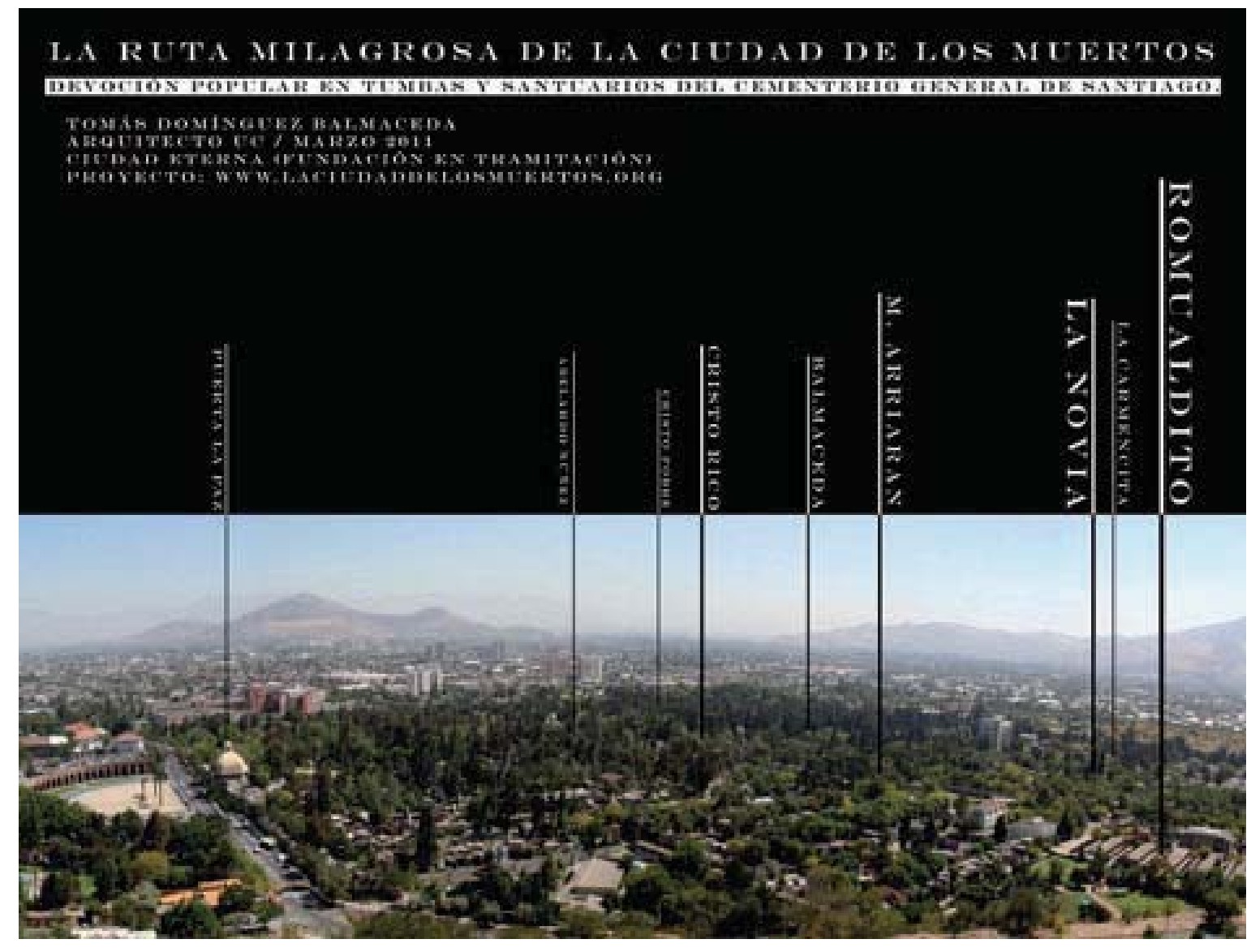

dadivosas; donde debía ver olvido y dolor, vi presencia, recuerdo afectuoso y conmemoración. Entendí que para estudiar el Cementerio tenía que sacar sus secretos desde las sombras del tabú de la sociedad de bienestar y reñir con la ceguera de nuestra cultura racionalista y que a veces vaga ignorando sus tradiciones y sus raíces ancestrales.

Para estudiar las proximidades de la muerte, fue necesario crear una óptica adecuada y la mirada metodológica desarrollada por la Ciudad de los Muertos, fue la del lente patrimonial pulido tras años de observación y reflexión, porque hasta entonces no existía una disciplina o especialidad en la materia. Otro problema inicial fue el desinterés general que existía por los estudios patrimoniales sumando al estigma cultural contra los cementerios y que ya se ha disipado parcialmente. Sin embargo lo más difícil fue afrontar la ausencia de información sobre el pasado del Cementerio General, la inexistencia de estudios serios, pocas publicaciones y la pérdida ocurrida cuando fueron eliminados todos sus documentos antiguos al resultar dañada la capilla del Cementerio de Disidentes por el terremoto de 1985, que para entonces era usada como bodega y archivo. ¿Cómo reconstruir una historia de la que casi no quedaban rastros? La respuesta la encontré en terreno, donde hallé un universo inagotable de fragmentos, en lo que hasta entonces era un laberinto caótico de miles de puertas hacia el pasado y que hubo que ir conociendo, dibujando, describiendo, registrando, clasificando, descifrando y abriendo.
ANEXO

RECORRIDO INAUGURAL DE LA RUTA MILAGROSA

Sábado 2 de abril de 2011, 11:00 a.m.

Palabras para la presentación de la Ruta Milagrosa:

Cristo Rico: Por favor intercede para la resurrección del Cementerio General?.

Profesor Núñez: Por favor interceda para que nuestro gobierno reconstruya, proteja, estudie y difunda el patrimonio cultural del Cementerio General de Santiago y de los demás cementerios históricos del país ${ }^{8}$.

Cristo Pobre: Por favor intercede por la paz del descanso de los muertos y por los pobres de solemnidad ${ }^{9}$.

San Balmaceda: Te ruego para que los demás presidentes de Chile apoyen esta nuestra lucha ${ }^{10}$.

Noviecita: Por favor intercede para que cada hombre que busca amor, encuentre a la mujer que lo espera.

Carmencita: Te ruego para que todas las tumbas tengan tantas flores como la tuya.

Romualdito: Libra al Cementerio de mentirosos y ladrones ${ }^{11}$.

Don Manuel: Por favor interceda para que la Dirección del Cementerio General sea pulcra, humanitaria y progresista y para que la reconstrucción prospere ${ }^{12}$. 


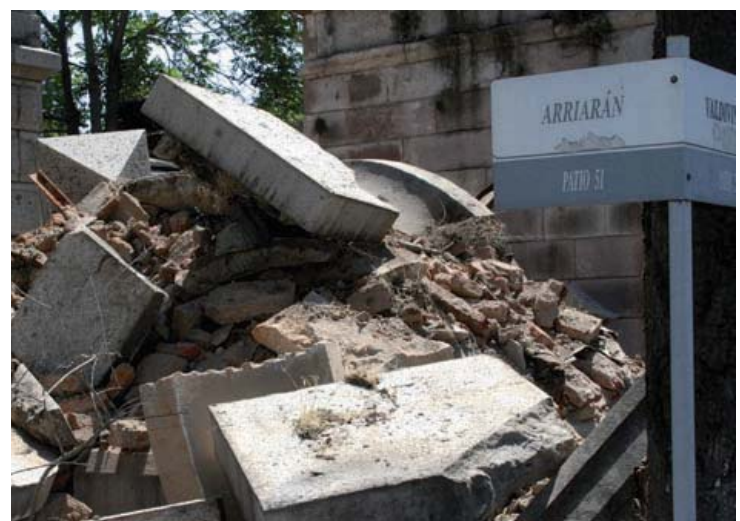

Figura 13 Manuel Arriarán, Patio 51

\section{NOTAS}

1. La creación del decreto $\mathrm{N}^{\circ} \mathbf{7 2 - 1}$ de enero del 2010 (Mineduc), significó el reconocimiento por parte del Estado Chileno de la existencia de un bien cultural declarado de interés nacional, asumiendo obligaciones y deberes sobre miles de tumbas y mausoleos históricos, dotando a estos inmuebles de nuevas facultades como beneficios fiscales, la posibilidad de acogerse a la Ley de Donaciones Culturales para restauraciones o reconstrucciones de hasta el $100 \%$ de los daños de un sismo, la posibilidad de participar del mercado de seguros antisismos al estar identificados sus valores físicos (costo de reconstrucción o daño material) y sus valores inmateriales (perjuicio irreparable o daño moral), etc.

2. En pesos (2011), la tasación del valor material de estos 2.434 monumentos sumó $\$ 152.000 .000 .000$. El valor inmaterial (factor de 3,79 ) incrementó la tasación del conjunto en $\$ 424.000 .000 .000$, sumando una riqueza patrimonial agregada (material + inmaterial) de $\$ 576.000 .000 .000$. De estas cifras se desprende que hasta antes de la declaratoria de Monumento Histórico la herencia cultural per cápita (entre 18.000.000 de habitantes) aportada por el Cementerio General a cada chileno se podía medir en $\$ 8.444$, lo que se incrementó a \$32.000 per cápita. De acuerdo a esto estimamos en $\$ 23.556$ por persona, el incremento de capital cultural y que definimos como la rentabilidad social de esta iniciativa.

3. El trabajo en terreno fue costeado en parte por recursos de un Fondart 2006 (6\%) en el área de investigación del patrimonio cultural y los resultados fueron sistematizados y analizados entre el 2007 y el 2011. Otro aporte de fondos públicos del Fondart 2008 (4\%) sirvió para sistematizar y condensar este conocimiento en una carpeta (Expediente Técnico) realizado para solicitar la declaratoria de monumento nacional.

4. Expediente Técnico que solicita la declaratoria de Monumento Nacional del Cementerio General de Santiago.

5. Expediente Técnico que solicita la declaratoria de Monumento Nacional del Cementerio General de Santiago.
6. Recuperado de sitio web http://urbatorium.blogspot.com

7. Milagro necesario para terminar con la agonía del Cementerio General, revertir el proceso de abandono y obsolescencia que se arrastra por décadas y de la decadencia institucional, la corrupción, la sobre explotación y el desplome de las cifras, todo lo que amenaza con un cierre de servicios a mediano plazo.

8. Aunque todo ello es una obligación, una necesidad y una vocación del Estado, hoy la situación es la opuesta y es necesario un milagro para invertir esa realidad.

9. Mucha conmoción han creado casos de reventas de tumbas y de la perturbación sistemática del descanso de los muertos. Se necesita un milagro para volver a dar credibilidad institucional. Los nombres de los pobres de solemnidad (los antiguos ocupantes de las fosas comunes quienes son enterrados sin cobro en tumbas temporales y hoy incinerados anónimamente), desde siempre han sido borrados de la memoria colectiva y seguirá ocurriendo a lo pobres que mueren hoy. Se necesita un milagro para recuperar la solemnidad de los pobres.

10. Fracasaron las gestiones con la presidenta Bachelet y del actual gobierno mejor no hablar. Tumbas de ex presidentes como Francisco Antonio Pinto cubierta de malezas o el mausoleo de José Joaquín Prieto usado de bodega, son situaciones para lamentar. Hoy viven cuatro ex presidentes. Confiamos en que contamos con el respaldo de los ex presidentes, pero es necesario un milagro para revertir la actual tendencia.

11. Cúmulos de mentiras y robos de tumbas y obras de arte, son una lacra que desangra el patrimonio del Cementerio General. Es necesario un milagro después de todo lo que se ha hecho y los magros resultados obtenidos.

12. El octavo punto de la ruta es el de don Manuel Arriarán, personaje olvidado y a quién se le pide un favor por haber sido director del Cementerio General entre 1880 y 1906, administración que llevó a cabo el Plan de Transformación que convirtió a un camposanto parroquial católico en una necrópolis laica del tamaño actual. Después de haberse dedicado toda su vida a la beneficencia, donó en su testamento 100.000 urnas de madera para que los pobres fueran enterrados con dignidad. No tuvo descendencia y el 27 de febrero su mausoleo colapsó completamente y no hay quién se haga responsable. Es necesario un milagro para que se reconstruya y se le vuelva a dar digna sepultura.

\section{BIBLIOGRAFÍA}

Ariès, Philippe (1983). El hombre ante la muerte. Madrid: Editorial Taurus, primera edición 1983, reimpresión 1987.

Edwards Bello, Joaquín. (1974). "Crónicas". Santiago de Chile: Editorial Zig-Zag, 4a edición.

Domínguez Balmaceda, Tomás (2008). Expediente Técnico que solicita la declaratoria de Monumento Nacional del Cementerio General de Santiago. 
(2008). Informe sobre reconstrucción del Cementerio General. 2010-27-02 a 2011-11-01. Recuperado de

www.laciudaddelosmuertos.org/wp-content/uploads/2011/11/

informe-sobre-reconstruccion-cementerio-general-web.pdf

(2009). La declaratoria de Monumento Nacional del Cementerio General de Santiago. X Encuentro de Cementerios Patrimoniales.

Recuperado de http://www.laciudaddelosmuertos.org/?p=1019

(2010). Informe de Daños del Terremoto en el Cementerio

General. Recuperado de http://www.laciudaddelosmuertos.org/

$? \mathrm{p}=1369$

León León, Marco Antonio (1997). Sepultura sagrada. Tumba profana. Los espacios de la muerte en Santiago de Chile, 1883-1932. Santiago: LOM Ediciones.

Ojeda Ledesma, Lautaro y Torres Bravo, Miguel (2011). Animitas. Deseos cristalizados de un duelo inacabado. Santiago: Consejo Nacional de la Cultura y las Artes \& LOM Ediciones.

Rosales, Justo Abel (1888). Sepulcros y Difuntos, Noticias históricas $i$ tradiciones, sobre el Cementerio Jeneral de Santiago. Santiago: Imprenta Estrella de Chile.

Vicuña Mackenna, Benjamín (1877). La ciudad de los muertos, en Chile. Relaciones Históricas. Santiago: Rafael Jover Editor.

// 